be readily seen by comparing the thoroughly Aryan structure of the few sentences of old Graulish extant.

Those are the races which have been inferred in the course of these remarks, in which I have proceeded on the principle that each successive band of conquerors has its race, language and institutions eventually more or less modified by contact with the race, language and institutions of those whom it has conquered. That looks simple enough when stated so, but the result which we get proves complicate. In any case I have endeavoured in this address to substitute for the rabble of divinities and demons, of fairies and phantoms that disport themselves at large in Celtic legend, a possible series of peoples, to each of which should be ascribed its own proper attributes. But that will only be possible if we can enlist the kindly aid of the Muse of Archæology.

\section{THE INTERNATIONAL CONGRESS OF APPLIED CHEMISTRY.}

THIS congress was held in Paris during the last week of July, M. Moissan being president and M. Berthelot honorary president. The work was divided into ten sections : analytical chemistry, chemical industry of inorganic products, metallurgy, mines and explosives, chemical industry of organic products, the sugar industry, chemical industry of fermentation, agricultural chemistry, hygiene, food analysis, medical and pharmaceutical chemistry, photography, and electrochemistry. More than two hundred papers were read and discussed, and numerous resolutions were passed, of which the following were the most important. In view of the great inconvenience caused commercially by uncertainty in the atomic weights used by analytical chemists, the congress, hoping that the adoption of the atomic weight of oxygen as a base $(O=16)$ would lead to a greater certainty and to a simplification in the calculation of atomic weights, agreed to work in unison with the International Commission on atomic weights. It further suggested the necessity for an International Commission for fixing methods and coefficients of analysis in commercial work. Committees were also appointed to deal with questions of indicators in volumetric work, analysis of manures, potash estimation, and the use of sulphurous acid in wine. In the second section the chief questions dealt with were the determination of high temperatures, construction of glass and porcelain furnaces, the manufacture of sulphuric acid, and of barium and hydrogen peroxides. In the section of metallurgy, mines and explosives, papers were read dealing with the sampling of minerals, the constitution of iron and steel, the use of the microscope in the study of metals, utilisation of waste heat, and the estimation of sulphur, manganese and phosphorus in metals. In the section dealing with the industry of organic substances the most important discussion was on the use of alcohol for other than drinking purposes, and a series of resolutions was passed stating that in the opinion of the congress no duty should be charged upon alcohol used in the preparation of pharmaceutical and chemical products. In the case of alcohol intended for use as fuel, the sub stances added should be of a character appropriate to its use, not too costly, and not containing any non-volatile substance. Any attempt to recover pure alcohol from methylated spirit should be liable to severe penalties, and all makers of stills should be compelled to give particulars to the excise authorities of stills sold or repaired. In the other sections discussions were held on the relation of the sugar industry to the State, the methods of analysis of wines and spirits, the carbide industry, manufacture of percarbonates, and numerous other papers of interest.

\section{UNIVERSITY AND EDUCATIONAL} INTELLIGENCE.

IT is officially announced that Mr. L. R. Wilberforce, demonstrator in physics at the Cavendish Laboratory, Cambridge, and University lecturer in physics, has been appointed to the Lyon Jones chair of experimental physics at University College, Liverpool, vacated by the removal of Dr. Oliver Lodge to the University of Birmingham.

The Admiralty has created an important new post in the Dockyard staff, namely, that of electrical engineer, to rank next to the four chief assistant engineers. To fill this post the Admiralty has chosen Mr. Louis J. Steele, M.I.E.E., late chief engineer of Messrs. Verity, and formerly assistant engineer with Messrs. Johnson and Phillips. Mr. Steele received his NO. I6i2, VOL. 62] training at the Technical College, Finsbury, under Prof. Silvanus Thompson and Prof. Perry, and carried off the certifcate of the College in 1890 . He will be attached to the Dockyard staff at Portsmouth.

InstRUCtion in chemistry is well provided for at the Goldsmiths' Institute, New Cross. During the session about to commence, Mr. W. J. Pope will give courses of lectures on oils, fats and waxes, organic chemistry with special reference to recent work and current views, inorganic chemistry and stereochemistry. In this last course of lectures, the principles which form the foundation of stereochemistry will be discussed, together with the methods which have led to the discovery of stereoisomerism amongst compounds of carbon, nitrogen, tin and sulphur. Particular attention will be paid to the bearing of stereochemistry upon current chemical problems. Lectures in chemistry will also be given by Mr. Stanley J. Peachey.

DURING the past year the Degree of Doctor of Philosophy was conferred by twenty-two Universities in the United States upon 233 candidates. The distribution of these degrees among the various Universities, and the subjects taken, are dealt with in an article in Science. It appears that 120 of the degrees were granted to students of the humanities, and II 3 for scientific subjects. The tables show that the humanities are favoured at Havard and Yale Universities, and the sciences at Johns Hopkins, Columbia and Cornell Universities. Last year Johns Hopkins gave more than its proportionate share of degrees in chemistry, physics, zoology and physiology, Chicago in mathematics, geology, sociology and education, Harvard in physics, zoology and anthropology, Columbia in astronomy, botany, zoology and education, Yale in palæontology and psychology, Cornell in botany and psychology, and Clark in mathematics, psychology and education. The six science subjects in which most students presented theses are as follows:-Chemistry 26 , physics I5, botany 12, mathematics Ir, zoology II, psychology 9.

EVER since the funds were provided for technical education in this country, it has been insisted upon in these columns, and by men of science generally, that such education could only be profitably carried on by giving rational instruction in scientific principles instead of attempting to teach actual processes and trade methods, which are constantly in a state of flux on account of new developments. The most gratifying characteristic or educated opinion at the present time is the acceptance of this view; and it is especially noteworthy in connection with the substitution of nature study for agriculture in rural schools. In an address recently delivered before the Cheshire College or Agriculture, Prof. Robert Wallace dwelt upon the relation between the work of an agricultural school and actual farm work, and showed himself in complete sympathy with the view which has been expressed over and over again in these columns. Here is the case in a few words:- "What a young farmer should learn is not ordinary farm work, viz. to plough and harrow a given area in the day. He can become an expert at that kind of thing at home to greatest advantage, without cost for instruction, and at the same time prove a valuable aid to his father. He requires to be taught just those things which are not to be learned on an ordinary farm, to have explained to him the meaning of processes which are founded on scientific principles, and to become familiar with the common facts of those sciences which bear upon agricultural practice." If this had been borne in mind by Technical Instruction Committees in rural districts from the time they came into existence, their efforts would have received more encouragement from practical men, and have been attended with better results, than have been attained in many cases.

\section{SCIENTIFIC SERIALS.}

Transactions of the American Mathematical Society, vol. i. No. 3.-Wave propagation over non-uniform electrical conductors, by M. I. Pupin, is a paper read before the society in December last. The main object of it is the solution of a problem which, looked at from a purely mathematical point os view, can be stated as follows :-Find the integral of the partial differential equation $\mathrm{L} \frac{d^{2} y}{d t^{2}}+\mathrm{R} \frac{d y}{d t}=\frac{1}{\mathrm{C}} \frac{\delta^{2} y}{\delta s^{-}}$, and determine it so as to satisfy $k+2$ boundary conditions, where $k+1$ is the number of coils. The principal difficulty is to determine 